\title{
Erratum to: Contemporary crustal velocity field in Alpine Mediterranean area of Italy from new geodetic data
}

\author{
Gregorio Farolfi $^{1,2} \cdot$ Chiara Del Ventisette ${ }^{1}$
}

Published online: 22 February 2016

(C) Springer-Verlag Berlin Heidelberg 2016

\section{Erratum to: GPS Solut \\ DOI 10.1007/s10291-015-0481-1}

In the original publication, Fig. 6 was incorrect. The North and East components of velocity vectors were inverted. The correct version of the Fig. 6 is shown here.

The online version of the original article can be found under doi:10.1007/s10291-015-0481-1.

Gregorio Farolfi

gregorio.farolfi@gmail.com

Chiara Del Ventisette

chiara.delventisette@unifi.it

1 Department of Earth Sciences, University of Firenze, Via La Pira 4, 50121 Florence, Italy

2 Istituto Geografico Militare, Via Battisti, 10/12, 50121 Florence, Italy

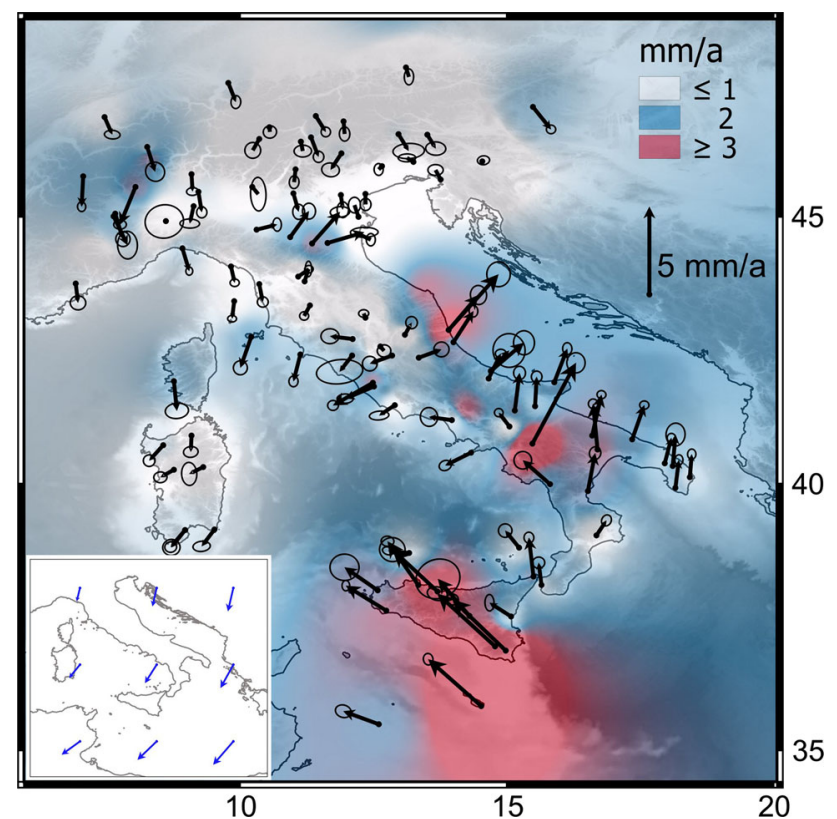

Fig. 6 Horizontal velocities and error ellipses (95\% of confidence level) in the local reference frame defined for the Alpine Mediterranean area. The interpolated horizontal velocity field is displayed by a graduated color scale. White represents stable part, blue $2 \mathrm{~mm} / \mathrm{a}$ and red up to $4 \mathrm{~mm} / \mathrm{a}$. Velocity field vectors of the Alpine Mediterranean Euler Pole with respect to the Eurasia are shown in the inset 